\title{
Financing of low resource intensity technology of Arctic industrial enterprises
}

\author{
Vladimir Zharov ${ }^{1,2, *}$ and Viacheslav Tsukerman ${ }^{2}$ \\ ${ }^{1}$ Branch of Murmansk Arctic State University in Apatity, Lesnayast.29,184209 Apatity, Russia \\ ${ }^{2}$ G.P. Luzin Institute for Economic Studies of the Kola Science Centre of the RAS, Fersmanstr. \\ 24a,184209 Apatity, Russia
}

\begin{abstract}
For the Arctic municipalities, the actual problem of their sustainable development is the reduction of industrial emissions of pollutants into the environment together with production waste, and a decrease in the amount of already accumulated waste. The aim of the study is to develop a scheme for the provision of state financial support to industrial enterprises for the introduction of technologies that reduce the level of energy and resource capacity of production. A procedure for developing such support has been proposed in the form of a system of priorities and criteria for selecting industrial enterprises. The criteria for such a selection are formulated. It is proposed to use the imitational dynamic model of the enterprise's innovative development, which introduces an analytical relationship between the set target increase in the share of value added in the value of industrial products and the amount of investment in fixed capital necessary to achieve this goal. It is shown that using such a model to develop medium-term forecasts for the development of enterprises, it is possible to calculate the increase in the volume of basic taxes that will receive the budgets of all three levels of the Russian budget system.
\end{abstract}

\section{Introduction}

Most cities in the Russian Arctic zone (hereinafter - the Arctic) are single-industry towns where a large city-forming enterprise, usually in the mineral resource sector, operates, that is, it carries out extraction and primary processing of mineral resources. As a result of the activities of such enterprises an enormous amount of industrial waste has accumulated around cities mainly in the form of off-balance ore dumps, "enrichment tailings" and metallurgical slags that pollute the environment. Toxic substances partly enter the wastewater and non-recyclable gases are released into the atmosphere. For example, more than a billion tons of industrial waste accumulated around the town of Kirovsk in the Murmansk region. Thus for the Arctic cities and municipalities the problem of environmental planning and environmental safety management is extremely topical providing, firstly, reducing emissions of pollutants into the environment along with production waste $[1,2,3]$, and, secondly, reducing the

\footnotetext{
*Corresponding author: zharov_vs@mail.ru
} 
amount of waste already accumulated. Both of these tasks can be solved with the innovative technological development of industrial enterprises [4, 5, 6] including use of the best available manufacturing technologies developed reducing its energy intensity. However, this raises the question of financing the investments in technological and environmental innovations that can reduce the energy and resource intensity of production. It should be noted that the majority of large industrial Arctic enterprises do not have enough of their own financial resources to introduce the latest production technologies [7]. At the same time in accordance with Article 17 of the Federal Law of the Russian Federation FL No. 7 of 01.10.2002 (as amended on 07.29.2018) "On Environmental Protection" governmental support for the implementation of the best available technologies can be provided not only by providing tax breaks but also by allocating funds from the federal budget and the budgets of the regions of the Russian Federation. Thus this option of financing of the industrial enterprises environmental activities can also be attributed to the possibility of obtaining additional environmental finances.

At the end of 2014 Russia adopted the Federal Law "On Industrial Policy in the Russian Federation" [8]. Innovation policy of the state is an integral part of the industrial policy. It acquires particular importance in the implementation of the state strategy for the development of the Russian Arctic zone, because, first, the harsh climatic conditions of the macroregion require creation and use of such technologies and appropriate equipment that could work reliably for a long time $[9,10]$. Second, under such extreme conditions of the Arctic human labor should be as limited as possible, which requires using the latest technologies. On the one hand, in total it provides an increase in labor productivity and, on the other hand, reduces the cost of social infrastructure in the area of initial development. Thus the economic and environmental interests of the state are implemented more efficiently. However, the priorities of the state environmental policy remain to increase the living standard of the population in the Arctic regions and reduce the burden on the environment, which is especially sensitive to an increase in industrial waste. In this regard, the state should be extremely interested primarily in the industrial use of the best available innovative technologies.

In the Arctic the already operating or intending to operate companies should also be interested in innovative development of their production, since under the harsh natural conditions the direct labor costs significantly increases and accordingly investments in fixed assets of companies become more cost efficient. In addition the increase of workers' productivity associated with the use of modern machinery and technologies reduces indirect costs of companies to support the development of social infrastructure in previously undeveloped areas, but the pursuit of maximum profit pushes into the background the task of protecting the natural environment as environmental costs increase the cost of production.

Thus when implementing the state and corporate innovation policies a contradiction arises in the environmental sphere, which is easily eliminated if the state imposes substantially more severe environmental restrictions for industrial activities for the living conditions of population in the Arctic territories especially in new development areas. However for the introduction of the best available technologies by industrial companies and reduce the energy intensity of production the state and regions of the Federation should provide them with financial support. Thus the aim of the work is to 
consider the possibilities and conditions for the provision by the state and regions of such support as a special type of environmental finance

\section{Materials and methods}

Currently large Arctic industrial companies, especially fast-growing ones, in order to prevent violations of environmental legislation and payment of appropriate fines have to invest substantial amounts of financial resources in production ecology.

In accordance with Article 12 of the Federal Law 488 [8] stimulation of activities on using the best available technologies in industrial production is the support of innovative activities of industrial entities. The stimulation is carried out in the form of financial support by the state and regions including created by them state funds for industrial development when implementing special investment contracts concluded for a period of up to ten years. Article 10 states that the support may be in the form of using competitive mechanisms for the provision of subsidies with the inclusion of the indicators of use efficiency of the subsidies into selection criteria of the recipients. Moreover in case of failure to achieve such indicators fines in the amount of the total subsidies amount may be levied. In accordance with Article 14 of the Federal Law 488 a state information system is created in order to obtain information, necessary for implementation of the industrial policy including stimulation of industrial activities. It should contain information on the industrial entities and types of industrial products produced as well as forecasts for development of the entities.

Thus for implementation of financial support for introduction of the best available technologies as a direction of innovative industrial activity there should be created a system for analyzing and forecasting development of the industry of the state, regions, and industrial companies. Accordingly the state and regions of the Federation should, on the one hand, work out targets for innovative industrial activities development including introduction of the best available technologies into production and, on the other hand, form criteria for the selection of companies applying for financial support with the inclusion of indicators of use efficiency of the subsidies. In addition it is necessary to develop a mechanism for the implementation of such support, which is essentially a procedure for coordinating priorities, goals and objectives of state and corporate innovation policy.

The main principles that are the methodological basis of the mechanism for coordinating interests:

- principle of science, which implies the need for a systematic approach to analysis and complexity in the coordination of interests including a comprehensive approach in terms of factors and powers operating in this sphere;

- principle of compromise according to which with the conjugation of powers a solution can never be found that fully satisfies everyone;

- principle of adaptability means that the tools in the process of coordinating interests between the company and its enterprises as well as within the enterprises must be continuously improved and adapted to the changing external and internal environment;

- principle of structure that is in analysis and coordination of interests their structure should be defined by areas and functions allowing to determine the necessary 
methods as well as the hierarchy of interests according to the degree of importance and the level of mismatch making it possible to determine the order of approval procedures;

- the principle of unity of economic and social goals, which provides that the organization of processes aimed at minimizing costs, increasing competitiveness and profitability of a company should at the same time ensure humanization of the labor sphere, creation of conditions for full-fledged work activities, be understandable for structural units and team members;

- principle of efficiency means that the procedures for analyzing and reconciling interests should be economically justified that is to be more profitable, for example, than bringing the situation to the stage of conflict with subsequent resolution by methods of conflictology, for example, labor disputes.

It should be noted that the innovative goals of the region and corporations differ significantly in their content. The most important tasks of modern state innovation policy are formation of scientific, technical and innovation potentials adequate to the existing and future needs of these regions, the necessary infrastructure and resource provision for innovation activity at the initial stage. At the same time the current tasks are solved by methods such as appropriate distribution of budgetary financial flows, assisting the development of the most appropriate high-tech industries in the regions, developing regional training systems for scientific and technical personnel, integrating regions into national and global information networks, forming regional sections of the state scientific and technical and innovative programs, financial and organizational support of scientific and technical components of the regional development programs.

Together with the regions the state legislates the division of jurisdictions and powers and identification of joint competencies in terms of innovation activities. On the basis of the rights and powers granted the state ensures the formation of a unified system of state priorities and their implementation taking into account interests of the regions and their capabilities to enhance innovation activities. At the same time special attention is paid to the development of regional scientific and technical potential.

The most important direction of the regional innovation policy is to support functioning and development of regional technology transfer systems, reducing obstacles to the innovation process including that by coordinating and facilitating cooperation of activities of the main actors of the regional programs - universities, scientific organizations, knowledge-intensive high-tech enterprises. The fact that from the point of view of socio-economic development of a region scientific and technical activity is never an end in itself, is of fundamental importance. Any region is interested in raising its economy and the level of welfare of the population and since it cannot be achieved without effective scientific and technical support it becomes necessary to use the existing scientific and technological potential in the interests of the region as well as to combine scientific and technical activities with problems of socio-economic development of the region. In this regard the strategy of state regional innovation policy should be developed on the basis of the fundamental principle of the balance of interests of all government levels.

When using efficient technological (process and product) innovations industrial companies can and should increase value added. If process innovations are introduced at the enterprises decreases (with other things being equal) the share of material costs 
in the total costs of production and sales with an increase in the share of value added in it even if the total output does not increase. This as we showed in [11], on the one hand, leads to an increase in the contribution of companies to gross regional product (GRP), and, on the other hand, to an increase in value added tax (VAT) to the federal budget and regional budgets. At the same time share of wages and (or) share of profits in the share of value added and accordingly in the revenue from sales of industrial products may increase, which increases tax revenues to the budgets of the respective levels in the form of personal income tax (PIT) and profits tax as well as the amount of insurance contributions to state social extra budgetary funds.

If product innovations are introduced and companies start to produce new innovative products then in this case they at a minimum increase total value added since such products begin to shape their demand from customers and accordingly their production and sales volume increases. At the same time in the initial period of production there may be no profit but the share of wages in the structure of value added may increase. Thus when introducing such type of technological innovations the taxable base expands.

As a result innovative activities of industrial companies always lead to an increase in value added and GRP of the regions, where such companies are located as well as the gross domestic product (GDP) of the country. However if innovative products contribute to import substitution and (or) begin to be exported to other countries the contribution of companies producing them to GDP of the country is further increased due to the growth of exports and (or) net exports. Also when introducing innovative technologies import substitution of the equipment used can be provided.

All these are the advantages of the innovation policy of industrial companies and the state authorities if they support such a policy. A possible flaw is essentially the only one. Since technological innovations as a rule lead to an increase in labor productivity and a possible reduction in the number of working personnel the regions of the Federation may decrease tax revenues from the collection of PIT and reduce insurance contributions to state social extra budgetary funds.

\section{Results and discussion}

Thus federal and regional authorities when conducting active innovation and environmental policies can and should stimulate companies to introduce technological innovations in the form of innovative projects that significantly reduce emissions of pollutants into the environment. As a result a system of priorities for an innovative industrial policy in the field of environmental activities and a system of criteria for the selection of industrial enterprises that are most appropriate for financial support can be formed.

Such support is intended only for innovatively active industrial companies whose value added has increased in a retrospective period of time due to the introduction of technological innovations including those in the form of the best available technologies. To clarify this circumstance it is necessary for each enterprise applying for financial assistance to calculate the values of the coefficient of production manufacturability level for the last three to five years and on this basis determine the stages of the technological development life cycle [12] since innovatively efficient development 
that ensures a simultaneous decrease in the material consumption of production and an increase in labor productivity is possible only at one stage out of six possible.

The total minimum annual amount of financial support to industrial companies implementing the best available technologies from the Federal and regional centers can be calculated basing on the increase in payments of VAT, PIT and profits tax in the respective budgets of regions of the Federation and the Federal budget for the last reporting year. At the same time the Federal Center should mainly provide financial support to those industrial enterprises that implement the best available technologies for the production of new goods and either export products or provide import substitution. As a rule, such enterprises are large and strategically important for the state.

Since the amount of financial support is always limited it is necessary to determine the economic effect of increasing their level of innovation activities to form a rating (priority) of companies that need it. At the regional level the following expression can be used:

$$
E=\Delta T-\Delta P I T
$$

where $\Delta \mathrm{T}$ - total increase in tax payments of a company to the regional budget as a result of a decrease in material intensity of production, an increase in labor productivity and an increase in profits over the analyzed period of time;

$\Delta$ PIT - possible reduction of the tax on personal income while cutting the company's staff.

To perform the analysis an annual financial reports of companies and data from tax authorities should be used.

Financial support can be provided for several years therefore, firstly, it should only come to those companies that from the point of view of the region can use it most efficiently. Secondly, it requires the time factor accounting. As a result the criterion according to which innovation activities of industrial companies can be stimulated to introduce the best available technologies will be as follows:

$$
\sum_{n}^{i=1} \frac{F A R_{i}}{(1+r)^{i}} \div \sum_{n}^{i=1} \frac{\Delta T_{i}}{(1+r)^{i}} \rightarrow \min
$$

where FARi - financial assistance of the region to the company in the i-th year of the perspective period;

$\Delta \mathrm{Ti}$-increase in tax revenues from the company to the regional budget in the $\mathrm{i}$-th year of the perspective period;

$\mathrm{r}$ - discount coefficient.

Thus the criterion minimizes the payback period of financial assistance from the region, which ensures the comparability of different amounts of financial resources for different companies in the context of their limitations. It can also be used to make decisions on financial assistance to newly created companies that intend to use the most promising and best available technologies. However in this case the possible increase in tax payments can be calculated on the outcome of the future activities of such a company in general and not only on the likely increase in the volume of value added and (or) changes in its cost structure. 
At the federal level calculation of economic effect of increasing industrial companies' innovation activities, in addition to increase in tax payments, should take into account a possible tax on exported goods and a decrease in government spending on import of goods in case of import substitution:

$$
E=(\Delta T+V E+\Delta I)-\Delta I C S F
$$

where $\Delta \mathrm{H}$ - total increase in tax payments of a company to the federal budget as a result of a decrease in the material intensity of production, an increase in labor productivity, and an increase in profits during the analyzed period of time;

$\triangle \mathrm{ICSF}$ - possible reduction in insurance contributions to the state extra budgetary social funds while reducing the company's employees;

$\mathrm{VE}$ - volume of export duties when implementing innovative goods for export;

$\Delta \mathrm{I}$ - federal budget savings from import substitution.

As a result the criterion of priority selecting of enterprises for providing financial support from the federal budget is the following expression:

$$
\sum_{n}^{i=1} \frac{F A F_{i}}{(1+r)^{i}} \div \sum_{n}^{i=1} \frac{\Delta T_{i}}{(1+r)^{i}} \rightarrow \min
$$

where FAFi - financial assistance of the Federal budget to the enterprise in the i-th year of the perspective period;

$\Delta$ Ti-increase in the volume of tax revenues from the enterprise to the Federal budget in the I-th year of the perspective period;

$\mathrm{r}$ - discount coefficient.

For the practical use of criteria (2) and (4) industrial companies should develop forecasts of their innovative development for 5-10 years using appropriate mathematical models that will be part of the environmental management system. The most dynamically developing modeling method, which makes it possible to most adequately reflect the properties of the object being modeled in the model being formed is simulation modeling [13]. By now a large number of simulation models have been developed and experimentally tested describing with varying degrees of detail the behavior of economic systems of different hierarchy levels: the national economy as a whole, individual regions, industries and industrial companies [14]. However the basis of almost all simulation models is the use of a more or less complex production function (or a system of functions) that links the results of the economic system activities with indicators of production factors use - first of all labor and capital (as production assets) [15]. At the same time in our opinion the wide use of the apparatus of production functions and correlation and regression analysis in simulation modeling does not allow adequately enough reflect the essential characteristics and interrelationships of the simulated object in the model being developed, and the model itself becomes incomprehensible by persons for use by which it is developed, since most economists who are practitioners in the field of economic management rather poorly perceive the "dry" mathematic modeling language.

The way out of this situation, in our opinion is first of all, in the use in the process of modeling not physical and volume-and-value indicators but cost and financial-cost ones. Then there is no need to use production functions, i.e. development of the economic system becomes possible to describe by reflecting the interrelations of the indi- 
cators on the basis of balance ratios. The advantage of this approach is also the fact that herewith a possibility to limit the number of variable control parameters of the model arises, which as noted in [16] is extremely important to increase the reliability of forecasts since it significantly reduces the field of development trajectories of the forecast object. In addition, in this case the model is described in terms familiar to the economists-practitioner, i.e. based on the use of indicators typical for economic analysis, planning and management.

A system of dynamic simulation models of analytical type, which allow determining the changing cost structure of any control object for any forecast period and calculating the values of interconnected technical, technological, environmental, economic, financial and economic indicators, has been developed.

In such models of company development two control parameters are used to perform calculations: the growth rate of sales revenue and of average monthly wages whose mutually agreed change in at certain intervals for each forecast period (one year, five years) ensures financial stability of the forecast object. When the model is used to justify options for innovative development of companies with introduction of the best available promising technologies and development of measures to stimulate an increase in innovative activities the share of value added in the cost of companies' production may be the indicator of the implementation level of the best available environmental technologies. Accordingly an increase in this share in the future may be another control parameter. Since the cost of products represents the sum of material costs and value added, then setting at the end of the forecast period the target value of the value added share in production cost leads to setting the target value of the share of material costs.

Thus as a result of analyzing the activities for the previous period (three to five years) for each individual company it is possible to determine the values of the coefficient of production manufacturability level, which essentially represents the ratio of fixed assets or their active part and the volume of material costs of the company. On this basis for the forecast period various variants of the coefficient values are formed. As a result the growth in the volume of fixed assets or their active part in the forecast period will be determined by multiplying the corresponding values of the coefficient of production manufacturability level by the predicted rate of change in the volume of material costs, whose value depends on the set values of two control parameters of the dynamic simulation model - growth rate of sales and share of value added in the forecast period.

In this case the logic of forming a simulation dynamic model to predict the development of the company will be as follows. Based on the previously determined value of growth of fixed assets and the averaged coefficient of their disposal, the required amount of input of fixed assets is calculated, i.e. the required amount of investment in fixed assets, which makes it possible to calculate the value of depreciation charges. If, based on the results of the company's previous activities, the value of the incremental capital-labor ratio is determined, then the increase in the company's personnel, and then the growth in labor productivity and possible increase in the average monthly wage are calculated. Accordingly the volumes of the possible salary fund and insurance payments to the state social funds are calculated, and also on the basis of a given growth rate of the volume of material costs their predicted volume in absolute terms is calculated. Other costs are determined on the basis of their previously established 
share in the total volume of the company's expenses for the production and sale of products.

After calculating all five cost elements the total costs of the company are calculated in the forecast period, as well as possible profit and net profit, whose amount together with the volume of depreciation charges is compared with the required volume of investments in the company's fixed capital. Accordingly if the company's own funds are not enough to ensure the preset growth rates of sales and achieve the target level of the share of value added, then either the specified values of these control parameters are adjusted downward, or the company turns to external sources of additional financing of investments. Then the simulation model is complemented with the developed financial unit. Accordingly when calculating such a model the possible volumes of all the main taxes, received by the budgets of all three levels of the budget system of Russia are calculated which will allow to efficiently use the system of stimulating environmental activities of industrial companies in the form of introducing the best available innovative technologies.

\section{Conclusions}

1. A new source of environmental finances for industrial companies operating in the Arctic, which is highly vulnerable to ecological imbalance due to the low level of assimilation of pollution may be financial support from the state and the regions at the expense of the funds of the respective budgets directed at implementation of the best available technologies.

2. For the practical implementation of such support the proposed system of priorities and criteria for the selection of industrial companies can be used involving the implementation of the best available innovative technologies that in the long term can reduce the energy and resource intensity of production and lead to the creation of environmental companies.

3. In the environmental and energy management system of industrial companies for selection of acceptable options for the introduction of the best available innovative technologies that ensure financial sustainability in the forecast period, the use of imitational dynamic model of analytical type that allows determining additional increase in basic taxes in the future has been proposed.

\section{References}

1. A. Kozlov, S. Gutman, I. Zaychenko, E. Rytova, P. Nijinskaya, IOP Conference Series: Materials Science and Engineering."6th International Scientific Practical Conference on Innovative Technologies and Economics in Engineering”, 012073 (2015) 
2. P.V. Druzhinin, G.T. Shkiperova, O.V. Potasheva, North and market: formation of economic order 3(54), 228-237 (2017)

3. P.V. Druzhinin, G.T. Shkiperova, Economic and social changes: facts, trends, forecast 2(32), 213-224 (2014)

4. V.S. Selin, F.D. Larichkin, V.A. Tsukerman, E.S. Goryachevskaya, Gornyi Zhurnal 10, 25-33 (2016)

5. N.I. Komkov, V.S. Selin, V.A. Tsukerman, E.S. Goryachevskaya, Studies on Russian Economic Development 28(1), 31-38 (2017)

6. N.P. Goridko, R.M. Nizhegorodcev, V.A. Tsukerman, Innovation vectors for economic growth of Northern regions: opportunities, estimates, forecasts (KSC RAS, Apatity, 2013)

7. V.A. Tsukerman, E.S. Goryachevskaya, North and market: formation of economic order 4, 70-86 (2015)

8. Federal Law of the Russian Federation of December 31.12.2014 No 488

9. V.V. Ivanter, The Arctic space of Russia in XXI century: development factors, the organization of management (St. Petersburg Polytechnic Peter the Great University, Nauka, Sankt Petersburg, 2016)

10. A.V. Kozlov, Integrated development of economic space of the Arctic zone of the Russian Federation (St. Petersburg Polytechnic Peter the Great University, Sankt Petersburg, 2016)

11. V.S. Zharov, Proceedings of the 2018 IEEE International Conference Quality Management, Transport and Information Security, Information Technologies (IT\&QM\&IS), 185-187 (2018)

12. V.S. Zharov, A.V. Kozlov, Proceedings of the 2018 IEEE International Conference "Quality Management, Transport and Information Security, Information Technologies"(IT\&QM\&IS). pp. 181-184. LETI, Sankt Petersburg (2018)

13. K.A. Bagrinovsky, V.V. Logvinets, Intelligent system in sectoral planning (Nauka, Moscow, 1989)

14. A.B. Levintal, F.F. Pashchenko, Indicative planning and regional policy (Finance and statistics, Moscow, 2007)

15. K.A. Bagrinovsky, T.I. Konnik, M.R. Levinson, Simulation systems of economic decision making (Nauka, Moscow, 1989)

16. S.M. Vishnev, Basics of integrated forecasting (Nauka, Moscow, 1977) 